\title{
Pharyngo-laryngeal histoplasmosis in an immunocompromised child-a case report
}

\author{
Arunabha Chakravarti ${ }^{*}$ DD, Rohini R. Nair ${ }^{1}$, Moazzam Mojahid ${ }^{1}$, Piali Mandal ${ }^{2}$, Jagdish Chandra ${ }^{2}$ and Anita Nangia ${ }^{3}$
}

\begin{abstract}
Background: Histoplasmosis is an endemic granulomatous fungal infection which rarely infects the larynx; less than 100 cases have been reported in medical literature till date.

Case presentation: A 6-year-old female child, a diagnosed case of B cell acute lymphoblastic leukemia since past 2 years and on chemotherapy, presented with hoarseness and dysphagia since past 2 months. Direct laryngoscopy revealed granular appearance of posterior pharyngeal wall and the supra-glottic larynx. Histopathological examination and bone marrow aspiration confirmed the diagnosis of disseminated histoplasmosis.

Conclusions: Pharyngo-laryngeal histoplasmosis should be considered in the differential diagnosis of an immunocompromised patient presenting with persistent hoarseness.
\end{abstract}

Keywords: Histoplasmosis, Disseminated, Immunocompromised, Pharyngo-laryngeal histoplasmosis, Case report

\section{Background}

Histoplasmosis is a non-contagious systemic fungal infection, caused by a thermally dimorphic fungus, Histoplasma capsulatum. The fungus thrives in warm and humid environment such as soils enriched with nitrogenous compounds and phosphates, derived from avian excreta and bat guano [1]. It has a worldwide distribution, with propensity of endemicity in North America $[1,2]$. Fewer cases have been reported from Asia and Europe.

The microconidia and short hyphal fragments of histoplasma, when inhaled by mammalian hosts reach the alveoli, followed by rapid conversion to its yeast form, that can persist in host tissues and may disseminate through the bloodstream and lymphatics to other organs, causing histoplasmosis [1].

The first description of histoplasmosis was done by a pathologist, Samuel Taylor Darling, in 1906, isolated during autopsy of a patient [3]. The diagnosis of histoplasmosis had always been made post-mortem until

\footnotetext{
* Correspondence: drachakravarti@yahoo.co.in

1 Department of Otorhinolaryngology, Lady Hardinge Medical College,

Connaught Place, New Delhi, India

Full list of author information is available at the end of the article
}

1934, when Dodd \& Tompkins diagnosed histoplasmosis in a living infant [3].

Paediatric cases occur in approximately 5\%, and in adolescents, it is higher. The disease occurs often in males than in females (1.5:1 ratio), and in ages between 6 and 9 years of age [4]. Histoplasmosis is usually self-limiting in immunocompetent children, while in immunocompromised children, the disease is more aggressive and disseminated [4].

Pharyngo-laryngeal histoplasmosis is a rare clinical entity, described first in 1940 by Brown and colleagues. Since then, less than 100 cases have been reported in medical literature $[2,5]$. Here, we present a rare case of disseminated histoplasmosis with primary pharyngolaryngeal presentation in an immunocompromised child.

\section{Case presentation}

A 6-year-old female child, with diagnosed case of B cell acute lymphoblastic leukemia on chemotherapy for last 2 years, was referred to the ENT department with complaints of hoarseness of voice and dysphagia since past 2 months. It was associated with history of intermittent fever and dry cough for 1 month. However, there was no history of night sweats or loss of weight.

\section{Springer Open}

(c) The Author(s). 2021 Open Access This article is licensed under a Creative Commons Attribution 4.0 International License, which permits use, sharing, adaptation, distribution and reproduction in any medium or format, as long as you give appropriate credit to the original author(s) and the source, provide a link to the Creative Commons licence, and indicate if changes were made. The images or other third party material in this article are included in the article's Creative Commons licence, unless indicated otherwise in a credit line to the material. If material is not included in the article's Creative Commons licence and your intended use is not permitted by statutory regulation or exceeds the permitted use, you will need to obtain permission directly from the copyright holder. To view a copy of this licence, visit http://creativecommons.org/licenses/by/4.0/. 
The general physical examination was unremarkable, except for mild hepato-splenomegaly. On examination of neck, bilateral level II and level III cervical lymphadenopathy was present. The oral cavity, ears, and nose were normal on examination. On flexible laryngoscopy, hypertrophic granulations were seen on posterior pharyngeal wall and oedematous, granular appearance of epiglottis, aryepiglottic fold, and false vocal cords was seen.

The blood profile showed that the child was anaemic (Hb $8.3 \mathrm{~g} / \mathrm{dL}$ ) with low platelet count (Plt 51,000 per cc). Peripheral smear showed normocytic normochromic RBCs with mild anisocytosis, reduced platelets but no hemo-parasites. Blood, sputum, and urine culture was sterile; viral markers for HIV, hepatitis B, and hepatitis $\mathrm{C}$ were negative. Sputum for Gram stain demonstrated normal respiratory flora. The chest X-ray was grossly normal. The FNAC picture from cervical lymph nodes was that of reactive lymphoid hyperplasia.

On direct laryngoscopy, under general anesthesia, hypertrophic granulations were seen over posterior pharyngeal wall and the whole of supra-glottic larynx (the epiglottis, aryepiglottic folds, arytenoids, and false vocal folds) was oedematous and granular in appearance (Figs. 1 and 2). The true vocal cords, sub-glottis, and trachea were normal (Fig. 2). Biopsy was taken from the granular tissue.
Histopathological examination showed a lining of stratified squamous epithelium with diffuse sheets of macrophages with interspersed mature lymphocytes (Fig. 3). The macrophages showed foamy cytoplasm, with numerous intracellular and extracellular histoplasma spores, which was positive for periodic acid Schiff stain. These spores also stained positive with Gomori's methanamine-silver stain, confirming the tissue diagnosis of histoplasmosis.

With the diagnosis of pharyngo-laryngeal histoplasmosis, CECT of neck, chest, abdomen, and bone marrow aspiration was done to rule out disseminated disease. On CECT, mild hepatosplenomegaly was seen. Bone marrow was normocellular with presence of intracellular yeast, thus confirming disseminated disease. However, the bone marrow culture was sterile. The urine and CSF cytology were negative for intracellular yeast and urine immuno-assay for histoplasma antibody was also negative.

The diagnosis of pharyngo-laryngeal histoplasmosis with dissemination was, thus, made. The patient was started on Inj. Amphotericin B (liposomal) $0.7 \mathrm{mg} / \mathrm{kg} /$ day for 2 weeks, followed by oral Itraconazole $75 \mathrm{mg}$ twice daily for 6 months. During follow-up, there were features suggestive of recurrence. So, duration of oral Itraconazole was increased by 2 months and no recurrence has been seen on 2 years of follow-up.

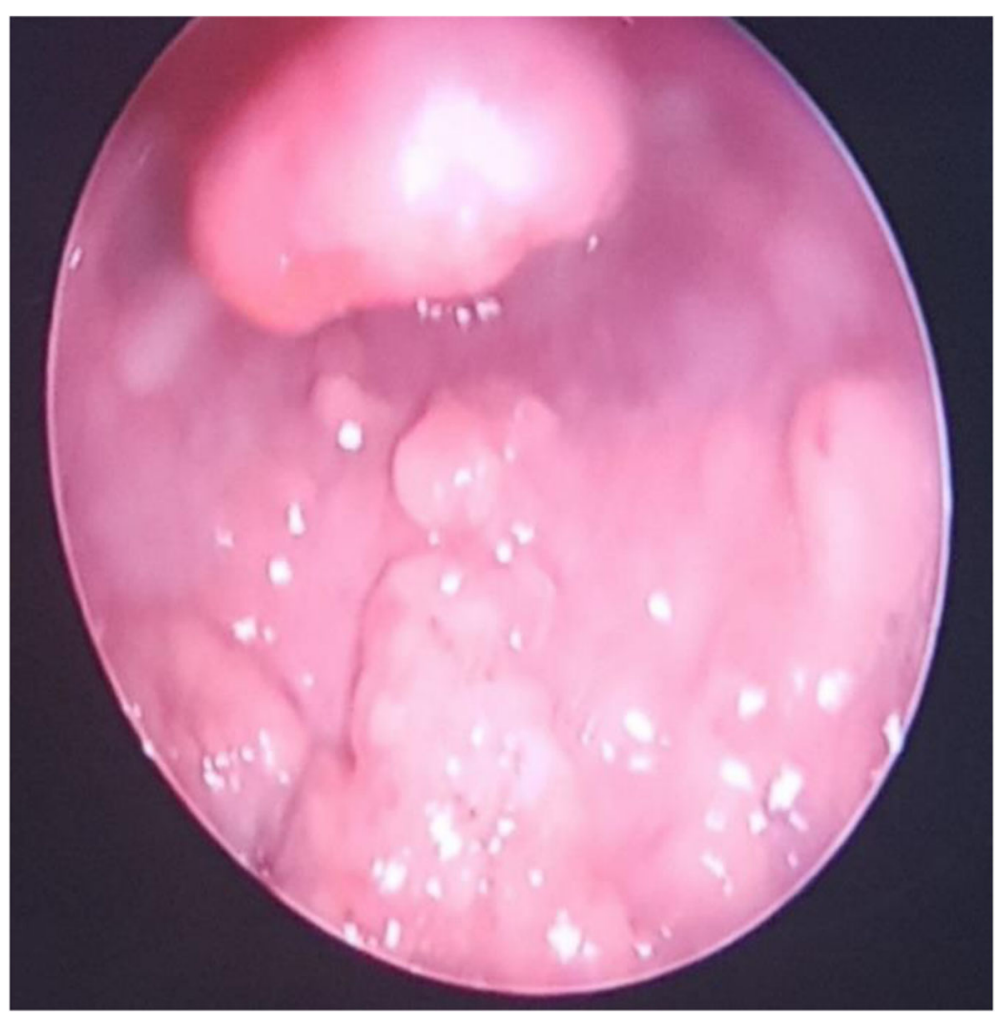

Fig. 1 Hypertrophic granulations over posterior pharyngeal wall with oedematous, granular epiglottis 

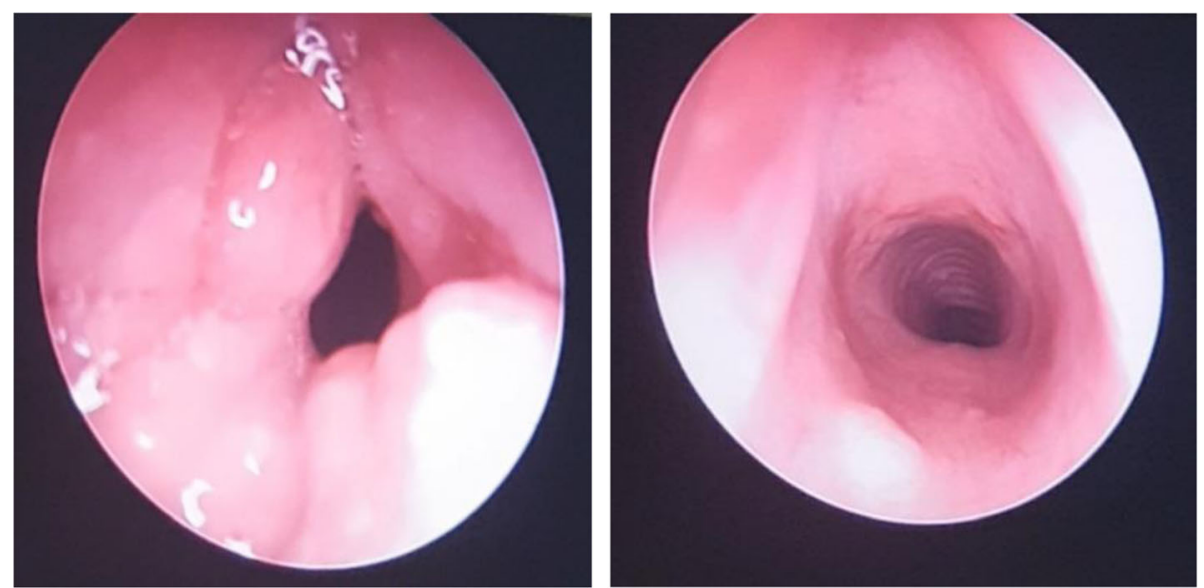

Fig. 2 Edematous and granular appearance of arytenoids, aryepiglottic folds and false vocal cords $(L>R)$. True vocal cord, subglottis, and trachea appears normal

\section{Discussion}

Histoplasmosis is a granulomatous disease of universal distribution caused by a dimorphic intracellular fungus, histoplasma capsulatum which mainly affects the reticular system [6]. Host factors like immunity, along with the amounts of organisms inhaled, affect its presentation and progression [7].

Clinically, it is classified into 4 types: acute pulmonary histoplasmosis, chronic pulmonary histoplasmosis, acute disseminated histoplasmosis, and chronic disseminated histoplasmosis [1].
Acute pulmonary histoplasmosis is the most frequent clinical form, accounting for $90 \%$ of the cases and presenting with dry cough, malaise, and multiple pulmonary infiltrates associated with hilar lymphadenopathy.

Disseminated forms are rare, occurring mainly in children less than 2 years, elderly and immunocompromised individuals. In healthy children, this condition is usually self-limiting, rarely requiring treatment but immunocompromised children, as the present case, are prone to develop more severe disease [8].

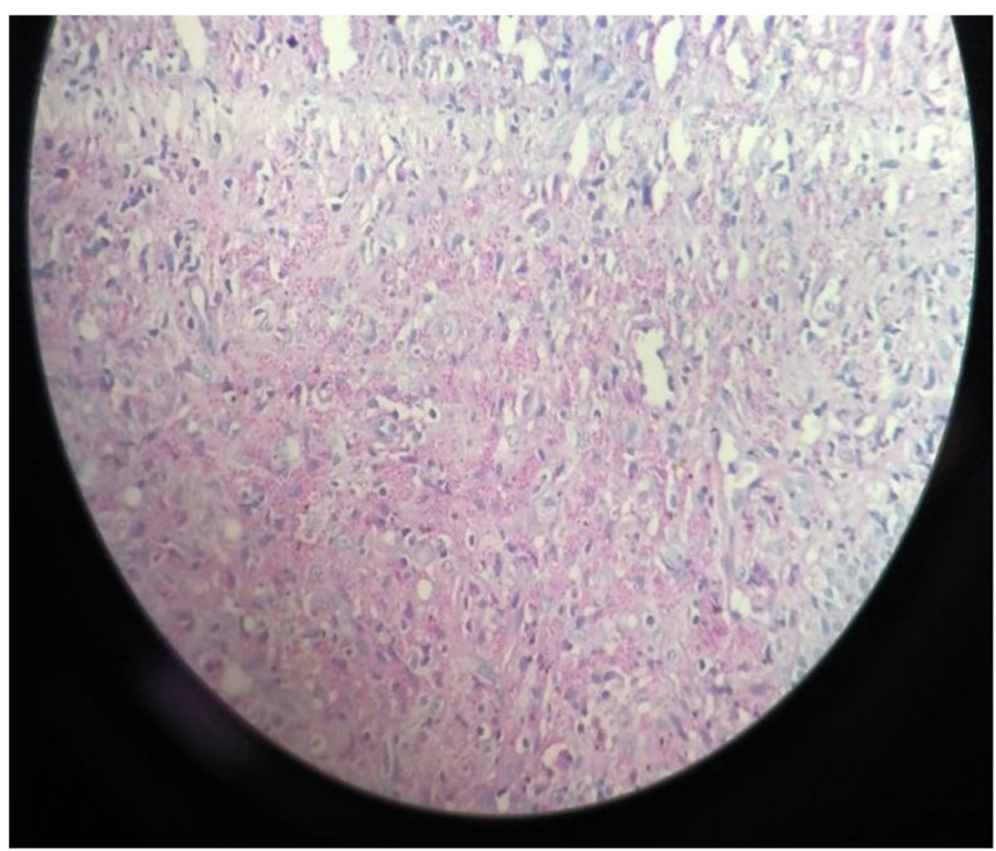

Fig. 3 HPE ( $\times 4$ magnification) showing lining of stratified squamous epithelium with diffuse sheets of macrophages with interspersed mature lymphocytes 
Histoplasma capsulatum infection involving the pharynx and larynx is a rare manifestation and is usually associated with mucocutaneous form of chronic disseminated spread. The initial manifestations usually are dysphagia, odynophagia, hoarseness of voice, gingival ulceration along with loss of weight, malaise, and fatigue [9].

Diagnosis of laryngeal histoplasmosis is rarely based on clinical examination and a set of differential diagnosis needs to be considered like amyloidosis, tuberculosis, lymphoma, syphilis, and sarcoidosis [2, 8]. Definitive diagnosis is based on histopathological examination of sputum, BAL, smears from ulcers in oral cavity, urine, bone marrow biopsies or oral/laryngeal masses with hematoxylin and eosin (H\&E), periodic acid Schiff, and Gomori's methenamine-silver nitrate stain, which can be confirmed by the growth of the fungi on Sabouraudchloramphenicol medium at $27^{\circ} \mathrm{C}$ for $10-14$ days [1].

Antigen detection in urine and serum should be done in all patients with suspected disseminated histoplasmosis. The enzyme immunoassay can detect the fungal antigen in $75-95 \%$ of the cases and in serum about $100 \%$ of cases; however, a negative antigen test does not rule out disseminated histoplasmosis [8]. Serological test for anti-histoplasma using immunodiffusion (RIA) and complement fixation methods (PCR) are positive in $70 \%$ of immunocompromised and $90 \%$ of immunocompetent patients with disseminated infection $[2,6]$.

In the present case, the diagnosis of disseminated histoplasmosis was based on histopathology and bone marrow aspirate examination.

Treatment of choice is intravenous Amphotericin B at $0.7-1.0 \mathrm{mg} / \mathrm{kg} /$ day for $2-4$ weeks, followed by oral itraconazole $5 \mathrm{mg} / \mathrm{kg}$ daily up to $200 \mathrm{mg}$ until clinical cure and then change to $50 \mathrm{mg} / \mathrm{kg}$ for 6 more months [8].

\section{Conclusions}

Pharyngo-laryngeal histoplasmosis is a rare presentation of disseminated histoplasmosis, making it a clinical challenge and requiring high degree of suspicion for diagnosis. It should be included in the differential diagnoses in immune-compromised patients complaining of persistent hoarseness and dysphagia. The prognosis is good with timely diagnosis and commencement of anti-fungal therapy.

\section{Abbreviations}

Hb: Haemoglobin; Plt: Platelets; HIV: Human immunodeficiency virus; CECT: Contrast-enhanced computed tomography; CSF: Cerebro-spinal fluid; BAL: Broncho-alveolar lavage; RIA: Radio-immuno assay; PCR: Polymerase chain reaction

\section{Acknowledgements}

Not applicable contributed to the manuscript; MM evaluated the clinical findings and contributed to the manuscript; PM was the treating paediatrician and referred the patient to ENT department; JC was the treating paediatrician and referred the patient to ENT department; AN performed the histopathological and bone marrow evaluations. All authors have read and approved the final manuscript.

\section{Funding \\ None.}

Availability of data and materials

Not applicable.

\section{Declarations}

Ethics approval and consent to participate

Not applicable.

\section{Consent for publication}

Verbal and written informed consent for publication was obtained from the parent of the patient. A copy of consent is available for the journal.

\section{Competing interests}

The authors declare that they have no competing interests.

\section{Author details}

${ }^{1}$ Department of Otorhinolaryngology, Lady Hardinge Medical College, Connaught Place, New Delhi, India. 'Department of Paediatrics, Lady Hardinge Medical College, Connaught Place, New Delhi, India. ${ }^{3}$ Department of Pathology, Lady Hardinge Medical College, Connaught Place, New Delhi, India.

Received: 27 November 2020 Accepted: 12 June 2021

Published online: 21 August 2021

References

1. Reibel JF, Jahrsdoerfer RA, Johns MM, Cantrell RW (1982) Histoplasmosis of the larynx. Otolaryngol Head Neck Surg 90(6):740-743. https://doi.org/10.11 77/019459988209000612

2. Ramadan O (2016) Laryngeal histoplamosis overview. Otolaryngol Open J 2(5):141-149. https://doi.org/10.17140/OTLOJ-2-130

3. Fischer GB, Mocelin $H$, Severo CB, de Mattos OF, Xavier MO, Severo LC (2009) Histoplasmosis in children. Paediatr Respir Rev 10(4):172-177. https:// doi.org/10.1016/j.prrv.2009.08.002

4. Bonifaz A, Estrada-Caraveo Y, Tirado-Sánchez A (2019) Epidemiology of endemic mycosis in children. Current Fungal Infection Reports 13(4):203210. https://doi.org/10.1007/s12281-019-00358-2

5. Sobrinho FP, Della Negra M, Queiroz W, Ribeiro UJ, Bittencourt S, Klautau GB (2007) Histoplasmosis of the larynx. Brazilian J Otorhinolaryngol 73(6):857-861. https://doi.org/10.1016/S1808-8694(15)31187-3

6. Coiffier T, Roger G, Beust L, Quinet B, Adam D, Dupont B, Garabedian EN (1998) Pharyngo-laryngeal histoplasmosis: one case in an immunocompetent child. Int J Pediatr Otorhinolaryngol 45(2):177-181. https://doi.org/10.1016/S0165-5876(98)00099-8

7. Bharathi MB, Malik E, Babu AR (2018) Atypical presentation of laryngeal histoplasmosis. J Case Reports 8(1):7-9

8. Moriones Robayo CA, Guerra Ortiz CP (2014) Laryngeal histoplasmosis: report first case in Colombia. Colombia Médica 45(4):186-189

9. Randhawa HS, Gugnani HC (2018) Occurrence of histoplasmosis in the Indian sub-continent: an overview and update. J Med Res Pract 7:71-83

\section{Publisher's Note}

Springer Nature remains neutral with regard to jurisdictional claims in published maps and institutional affiliations. 